\title{
Acute Respiratory Distress Syndrome in Mechanically-Ventilated Patients with Community-Acquired Pneumonia
}

\author{
Catia Cilloniz ${ }^{1}$, Miquel Ferrer ${ }^{1}$, Adamanthia Liapikou ${ }^{2}$, Carolina Garcia-Vidal ${ }^{3}$, Albert Gabarrus ${ }^{1}$, Adrian \\ Ceccato $^{1}$, Jorge Puig de La Bellacasa ${ }^{4}$, Francesco Blasi ${ }^{5}$, Antoni Torres ${ }^{1}$ \\ ${ }^{1}$ Department of Pneumology, Institut Clinic de Respiratori, Hospital Clinic of Barcelona - Institut \\ d'Investigacions Biomèdiques August Pi i Sunyer (IDIBAPS), University of Barcelona, Ciber de \\ Enfermedades Respiratorias (Ciberes) Barcelona, Spain. \\ ${ }^{2}$ Respiratory Department, Sotiria Chest Diseases Hospital, Mesogion 152, Athens, Greece. \\ ${ }^{3}$ Infectious Disease Department, Hospital Clinic of Barcelona, Spain. \\ ${ }^{4}$ Department of Microbiology, Hospital Clinic of Barcelona, Spain. \\ ${ }^{5}$ Department of Pathophysiology and Transplantation, Università degli Studi di Milano, IRCCS \\ Fondazione Cà Granda Ospedale Maggiore Policlinico, Milan, Italy.
}

\section{Corresponding authors:}

Antoni Torres and Miquel Ferrer.

Department of Pneumology, Hospital Clinic of Barcelona Villarroel 170, Barcelona 08036, Spain.

Phone +34932275549 . Fax +34932275549 .

Email: atorres@ub.edu; miferrer@clinic.ub.es

Financial support statement: This work was supported by Ciber de Enfermedades Respiratorias (CibeRes CB06/06/0028), 2009 Support to Research Groups of Catalonia 911, IDIBAPS (CERCA Programme / Generalitat de Catalunya).

Take-home message: In patients with community-acquired pneumonia, the incidence of acute respiratory distress syndrome based on the Berlin definition was $2 \%$ among all patients in hospital, $13 \%$ among patients in intensive care, and $29 \%$ among patients receiving mechanical ventilation. Acute respiratory distress syndrome was not related to the aetiology or mortality in this population.

Take-home message: In mechanically-ventilated patients with community-acquired pneumonia, ARDS based on the Berlin criteria was not related to the aetiology or mortality. 


\section{ABSTRACT}

Question: To assess the incidence, characteristics, aetiology, risk factors and mortality of acute respiratory distress syndrome (ARDS) in ICU patients with community-acquired pneumonia (CAP) using the Berlin definition.

Methods: We prospectively enrolled consecutive mechanically-ventilated ICU adults with CAP over 20 years, compared with mechanically-ventilated patients without ARDS. The main outcome was $30-$ day mortality.

Results: Among 5,334 patients hospitalized with CAP, 930 (17\%) were admitted to the ICU, and 432 required mechanical ventilation; 125 (29\%) cases met the Berlin ARDS criteria. ARDS was present in $2 \%$ of hospitalized patients and $13 \%$ of ICU patients. Based on the baseline $\mathrm{PaO}_{2} / \mathrm{FiO}_{2}, 60(48 \%), 49$ (40\%), and 15 (12\%) patients had mild, moderate, and severe ARDS, respectively. Streptococcus pneumoniae was the most frequent pathogen, with no significant differences in aetiology between groups. Higher organ system dysfunction and previous antibiotic use were independent risk factors for ARDS in the multivariate analysis, while previous inhaled corticosteroids was independently associated with a lower risk. The 30-day mortality was similar between patients with and without ARDS ( $25 \%$ vs. $30 \%, p=0.25)$, confirmed by propensity-adjusted multivariate analysis.

Conclusions: ARDS occurs as a complication of CAP in $29 \%$ of mechanically-ventilated patients, but is not related to the aetiology or mortality. 


\section{INTRODUCTION}

Community-acquired pneumonia (CAP) is associated with increased morbidity, mortality, and health costs ${ }^{[1,2]}$. The incidence of severe CAP requiring intensive care unit (ICU) admission is increasing, both because of septic shock and the need for invasive mechanical ventilation (IMV) ${ }^{[3]}$. Despite global efforts to improve outcomes, mortality remains high in severe CAP ${ }^{[4-6]}$. Streptococcus pneumoniae is the leading cause of CAP; it is the underlying etiological agent in $22 \%$ of patients requiring ICU admission ${ }^{[7]}$, and approximately $30 \%$ of these patients develop pulmonary complications during their clinical courses ${ }^{[8]}$.

Acute respiratory distress syndrome (ARDS) is a potential complication of severe CAP that is reported in approximately $3 \%$ of patients hospitalized with pneumococcal CAP ${ }^{[9]}$. This condition is characterized by the rapid development of severe acute respiratory failure, and is associated with high morbidity and mortality despite advances in supportive care and ventilator management ${ }^{[10,11]}$. However, there is limited information regarding the incidence of ARDS, associated pathogens, risk factors, and specific outcomes in hospitalized patients with severe CAP, especially in the era of the current Berlin definition, according to which patients must be receiving positive-pressure ventilation ${ }^{[12]}$. Although the overall survival from ARDS is improving ${ }^{[12,13]}$, mortality remains as high as $35 \%$, and disabling complications persist among ICU survivors, with recovery sometimes continuing for more than one year ${ }^{[13,14]}$. In addition, ARDS may be under recognized and undertreated ${ }^{[14]}$.

We hypothesized that patients with severe CAP and ARDS have a higher mortality than those patients who require mechanical ventilation without ARDS. The aim of the study was to assess the incidence, clinical characteristics, aetiology, risk factors and mortality of ICU patients with severe CAP and ARDS according to the new Berlin definition ${ }^{[12]}$, compared with ventilated patients without ARDS.

\section{METHODS}

\section{Study design and patients}

Please refer to the online Supplemental Material for full details of the methods. This was a prospective observational cohort study of consecutive adult patients with CAP admitted to the ICU within 24 hours of hospital admission, between November-1996 and December-2016. The inclusion criteria were as follows: 1 ) met the criteria for severe CAP ${ }^{[15]}$ and were admitted to the ICU, which included intermediate care units; and 2) received either IMV or non-invasive mechanical ventilation (NIMV) during the first 24 hours of hospital admission. Patients were excluded if they had severe immunosuppression or active tuberculosis.

\section{Data collection and evaluation}

The following were recorded at admission: age, sex, smoking history, alcohol and drug consumption, co-morbidities, antibiotic treatment in the 30 days before admission, treatment with oral and inhaled corticosteroids, clinical symptoms and signs, arterial blood gas measurements, and chest $\mathrm{x}$-ray findings. All chest $\mathrm{x}$-rays were reviewed by at least two co-authors, and consensus was required to define cases as ARDS or non-ARDS; we also assessed laboratory parameters, diagnostic procedures, empiric antibiotic therapy, ventilator support (IMV and NIMV), pulmonary complications, and other clinical events (cardiac arrhythmias, septic shock, and acute renal failure). Duration of treatment, length of hospitalization, and mortality were noted. Finally, we calculated the Pneumonia Severity Index (PSI) ${ }^{[16]}$ and the Sepsis-related Organ Failure Assessment (SOFA ${ }^{[17]}$ scores 
at hospital and ICU admissions.

\section{Microbiological evaluation and diagnostic criteria}

We collected sputum samples, and when available, pleural fluid, tracheobronchial aspirates, and bronchoalveolar lavage fluid. Sputum and blood samples were obtained for bacterial culture in the emergency department, before antibiotic therapy. Respiratory samples were processed for Gram and Ziehl-Neelsen stains and for bacterial, fungal, and mycobacterial cultures. Nasopharyngeal swabs for respiratory virus detection and urine samples for $S$. pneumoniae and Legionella pneumophila antigen detection were obtained within 24 hours of hospital admission. Blood samples for serology of atypical pathogens and respiratory viruses were taken at admission and in the third and sixth weeks thereafter. The criteria for etiological diagnosis can be found in a previous report ${ }^{[18]}$.

\section{Definitions}

Pneumonia was defined as a new pulmonary infiltrate on chest x-ray at hospital admission with symptoms and signs of lower respiratory tract infection. A prior episode of pneumonia was defined as a case within the past 12 months.

ARDS was identified within the first 24 hours of hospital admission based on the Berlin definition ${ }^{[12]}$ : new or worsening respiratory symptoms; bilateral pulmonary radiologic opacities, not fully explained by effusions; lobar/lung collapse or nodules, not fully explained by cardiac failure or fluid overload; and a $\mathrm{PaO}_{2} / \mathrm{FiO}_{2}$ (i.e., partial pressure of oxygen in arterial blood/fraction of inspired oxygen) $\leq 300 \mathrm{mmHg}$ with a positive end-expiratory pressure or continuous positive airway pressure $>5 \mathrm{cmH}_{2} \mathrm{O}^{[12,19]}$. The severity of ARDS was divided into three categories: mild $\left(200<\mathrm{PaO}_{2} / \mathrm{FiO}_{2} \leq 300\right.$ $\mathrm{mmHg})$, moderate $\left(100<\mathrm{PaO}_{2} / \mathrm{FiO}_{2} \leq 200 \mathrm{mmHg}\right)$ and severe $\left(\mathrm{PaO}_{2} / \mathrm{FiO}_{2}<100 \mathrm{mmHg}\right)^{[12]}$. We chose the initial 24 hours to differentiate as ARDS and non-ARDS patients because this period of time is considered the limit to differentiate between clinical features at admission and worsening evolution in the hospital [20]. Chronic obstructive pulmonary disease (COPD) was defined according to the 2017 GOLD strategy ${ }^{[21]}$.

\section{Clinical outcomes}

The primary outcome was 30-day mortality. Other outcomes were the hospitalization length, and the ICU and in-hospital mortality rates. Patients were followed for 30 days or until hospital discharge.

\section{Ethics statement}

The study was approved by the ethics committee of our institution (no. 2009/5451). The need for written informed consent was waived due to the non-interventional design.

\section{Statistical analysis}

Categorical variables are reported as number of patients (\%), whereas continuous variables are reported as median (interquartile range [IQR]) for non-normal distributions or as mean (standard deviation [SD]) for normal distributions. Categorical variables were compared using the $\chi^{2}$ test or the Fisher exact test, and continuous variables were compared using the $t$-test or the nonparametric Mann-Whitney test, as appropriate. The significance level was $p<0.05$ (2-tailed), unless otherwise specified. All analyses were performed using IBM SPSS Statistics, version 23.0 (IBM Corp., Armonk, NY, USA). 
Logistic regression analyses ${ }^{[22]}$ were used to examine the associations between ARDS and risk factors. First, each risk factor was tested individually. Second, all risk factors with an association in the univariate model $(p<0.15)$ were added to the multivariate model. Finally, a backward stepwise selection $\left(p_{\text {in }}<0.05, p_{\text {out }}<0.10\right)$ was used to determine factors associated with ARDS. The association with 30 -day mortality was tested by univariate and multivariate analyses with the same inclusion criterion $(p<0.15)$.

A propensity score was developed for patients with ARDS ${ }^{[23]}$. Together with the year of occurrence of pneumonia, the presence of ARDS, the microbial aetiology, and the interaction between ARDS and the microbial aetiology, this was incorporated into the multivariate logistic regression analysis to predict 30-day mortality. If two independent variables were highly correlated $(r>| \pm 0.30|)$, the variable with the largest variance was excluded from multivariate analysis ${ }^{[24]}$. The odds ratios (ORs) and $95 \%$ confidence intervals (Cls) were calculated.

The Hosmer-Lemeshow goodness-of-fit test was performed to assess the overall fit of the models. The areas under the receiver operating characteristic curves (AUCs) of the multivariate models were calculated to predict ARDS and 30-day mortality. Internal validation of the prediction models was conducted by ordinary nonparametric bootstrapping with 1,000 bootstrap samples and bias-corrected, accelerated $95 \% \mathrm{Cls}^{[25]}$. The same analyses were performed on the subset of patients with pneumococcal CAP. Finally, we used multiple imputation ${ }^{[26]}$ to handle missing data.

\section{RESULTS}

\section{Patients' characteristics}

Among 5,334 patients hospitalized with CAP during the observation period, 930 (17\%) were admitted to the ICU, of whom 462 (52\%) were not ventilated, 137 (15\%) received NIMV, and 295 (33\%) received IMV (Figure 1).

The study population comprised 432 patients treated in ICU with either IMV or NIMV: 125 cases (29\%) met the Berlin ARDS criteria, and 307 cases (71\%) did not. ARDS was present in $2 \%$ of all patients hospitalized with CAP and in $13 \%$ of those admitted to the ICU. According to the severity classification based on the baseline $\mathrm{PaO}_{2} / \mathrm{FiO}_{2}$ ratio, 60 (48\%), 49 (40\%), and 15 (12\%) patients had mild, moderate, and severe ARDS, respectively. Two patients had been ventilated in the prone position. None of them had received extracorporeal membrane oxygenation.

The patients' characteristics are shown in Tables 1 and 2. Compared to patients without ARDS, those with ARDS had less frequently received treatment with inhaled corticosteroids; had less chronic respiratory co-morbidity, particularly COPD; had poorer baseline oxygenation, higher organ dysfunction, and lower PSI risk; and had more multilobar involvement. However, there was only a trend to have less frequently received pneumococcal vaccination, for less frequent male gender, and more frequent prior antibiotic treatment.

\section{Microbiological diagnosis}

An etiologic diagnosis was obtained in 228 patients (53\%; Table 3). The most frequent pathogen in both groups was $S$. pneumoniae, with no significant differences in aetiology between the groups. Among the 100 cases of pneumococcal CAP, 29 met the ARDS criteria, the same proportion as in the overall population. 


\section{Empiric antibiotic therapy}

Data on empiric antibiotic treatment were available in 414 patients (96\%; Online Table 1). The most frequent regimens were $B$-lactam plus either a respiratory fluoroquinolone $(42 \%)$ or a macrolide (31\%). ARDS patients more often received a ß-lactam plus a respiratory fluoroquinolone compared with non-ARDS patients $(p=0.003)$.

\section{Predictors of ARDS}

Among the variables associated with ARDS in the univariate analysis (Table 4), a higher SOFA score and previous antibiotic treatment remained significant independent risk factors for ARDS in the multivariate analysis. Interestingly, prior treatment with inhaled corticosteroids was independently associated with a lower risk for ARDS. The AUC was $0.66(95 \% \mathrm{Cl}, 0.60-0.71)$ for the model predictive of ARDS (Online Figure 1). Internal validation of the logistic regression model by bootstrapping demonstrated robust results for all the variables in the model, with small $95 \% \mathrm{Cls}$ around the original coefficients (Online Table 2).

\section{Mortality and length of stay}

We did not find significant differences between groups regarding mortality or length of hospitalization (Table 5). However, in cases with pneumococcal CAP, mortality in ICU was higher among those with ARDS ( $p=0.026$; Online Table 3$)$, but neither the in-hospital mortality $(p=0.070)$ nor the 30-day mortality $(p=0.088)$ reached statistical significance.

According to ARDS severity, the 30 -day mortality rate was $32 \%, 33 \%$, and $60 \%$ for patients with mild, moderate and severe ARDS, respectively.

\section{Predictors of 30-day mortality}

Among the different variables associated with 30-day mortality in the univariate analysis (Table 6), the following were independent predictors of 30-day mortality in the propensity-adjusted multivariate analysis: older age, previous antibiotic treatment, other chronic pulmonary diseases (including only the sequelae of pulmonary tuberculosis, pulmonary hypertension, and interstitial lung disease), chronic cardiovascular and liver disease, higher SOFA score, and inadequate empiric antibiotic treatment. It was notable that having a previous episode of pneumonia and having received the pneumococcal vaccination were independently associated to a reduced 30-day mortality rates.

Overall, ARDS was not associated with 30-day mortality, even after adjustment for potential confounders. The AUC was $0.79(95 \% \mathrm{Cl}, 0.75-0.84)$ for the model predictive of 30-day mortality (Online Figure 2). Internal validation of the logistic regression model by bootstrapping with demonstrated robust results for all variables included in the model, with small $95 \% \mathrm{Cls}$ around the original coefficients. Finally, the same analysis in the subset of patients with pneumococcal CAP confirmed that ARDS was not independently associated with 30-day mortality after adjustment for potential confounders (adjusted OR, 1.77; 95\% $\mathrm{Cl}, 0.70-4.50 ; \mathrm{p}=0.23$ ).

\section{DISCUSSION}

The main findings of this study are as follows. First, based on the Berlin definition, ARDS was present in $2 \%$ of all hospitalized patients with CAP, $13 \%$ of those admitted to the ICU, and $29 \%$ of those ICU patients requiring mechanical ventilatory support. Second, higher SOFA scores and previous antibiotic use were independent predictors for ARDS among ventilated patients with CAP, 
while previous inhaled corticosteroid treatment was protective. Third, ARDS had no different aetiologies or mortality in patients requiring mechanical ventilation for CAP.

ARDS is recognized globally as a major clinical problem ${ }^{[13]}$, with pneumonia and extrapulmonary sepsis being the main risk factors in $75 \%$ of cases ${ }^{[14]}$. However, there has been a lack of information about the incidence of ARDS in CAP after the Berlin definition was proposed. Our data are consistent with those of the LUNG SAFE study ${ }^{[14]}$, which evaluated the incidence of ARDS in 459 ICUs in 50 countries. They reported that ARDS occurred in 10\% of all ICU admissions and in $23 \%$ patients who required mechanical ventilation. According to the Berlin criteria, $30 \%, 47 \%$, and $23 \%$ of their patients had mild, moderate, and severe ARDS, respectively. By contrast, there was a higher proportion of mild ARDS and a lower proportion of severe ARDS in our cohort.

Over the past century only a few small case series of ARDS in pneumococcal CAP have been reported [27-29]. A recent French multicenter study ${ }^{[30]}$ concerning pneumococcal CAP in the ICU indicated that the incidence of ARDS was $45 \%$, which was substantially higher than that reported in this study. However, those authors used the prior American-European consensus definition of ARDS ${ }^{[31]}$ and not the current Berlin definition, and included non-ventilated patients (16\%).

To our knowledge, this is the first study to provide data on the incidence of ARDS using the Berlin definition among patients hospitalized with CAP. We studied a cohort with severe CAP requiring mechanical ventilation, and compared those with and without ARDS. Regarding the independent predictors for ARDS, the association of higher organ system dysfunction to ARDS was to be expected because these patients had worse baseline oxygenation, an important component of the score.

We previously reported that inhaled corticosteroid use before admission in patients hospitalized because of CAP can reduce the systemic inflammatory response ${ }^{[32]}$, possibly with a selective modulation of the mechanisms of defences to infection [33], with reduced serum levels of tumour necrosis factor (TNF)-alpha, among others. This biomarker has been involved in the pathophysiology of ARDS [34].

We have no clear explanation for the independent association between previous antibiotic use and increased risk of ARDS. To our knowledge, this association has not previously been reported. We have shown that previous antibiotic use can be associated with antibiotic-resistant bacteraemia in patients with CAP ${ }^{[35]}$, resulting in more inappropriate therapy. Whether this could predispose patients to ARDS remains to be assessed. However, this association requires confirmation in future studies.

Mortality among ARDS patients was no different to that among ventilated non-ARDS patients. Indeed, even the propensity-adjusted multivariate analysis did not show an association between ARDS and patients' mortality. According to our results, we think that the expected association of ARDS with mortality seems more related to the need for mechanical ventilation in these patients with CAP rather than ARDS itself, as we have recently reported that invasive mechanical ventilation in patients with severe CAP independently predicts mortality [36]. However, we cannot exclude that specific populations of patients with CAP and ARDS may have different mortality, since sub-phenotypes of ARDS patients with different outcomes related to inflammation [37] or fluid responsiveness [38] have recently been proposed.

Independent predictors of mortality have previously been reported for CAP and other pulmonary infections in critically-ill patients, including older age, chronic liver disease ${ }^{[39]}$, chronic cardiovascular disease ${ }^{[39-41]}$, increased organ system dysfunction ${ }^{[42-44]}$, and inadequate empiric 
treatment ${ }^{[45]}$. It is not clear the reason for the association of previous pneumonia with lower mortality; possibly these patients might have developed a more effective immune response to infection. This is also consistent with pneumococcal vaccination being independently associated with reduced mortality. Given that ARDS was related to mortality in patients with pneumococcal pneumonia, previous vaccination might reduce disease severity in these patients.

Due to the association of ARDS with higher mortality in pneumococcal pneumonia, there is a need to develop effective preventive measures for this complication. A recent randomized clinical trial ${ }^{[46]}$ and a meta-analysis ${ }^{[47]}$ found that short-term treatment with corticosteroids can prevent radiographic progression and ARDS development in CAP. However, these studies investigated CAP in general, not pneumococcal pneumonia specifically. Studies focusing on the acute treatment of pneumococcal pneumonia with corticosteroids or other immunomodulators ${ }^{[48]}$ are therefore needed. Unfortunately, we have no systematic data on the number of patients who received pneumococcal conjugate vaccine-13 or pneumococcal polysaccharide vaccine- 23 .

In our opinion, the strengths of this study are the large sample, the prospective and consecutive data collection, the use of the current Berlin definition for ARDS, and the statistical analysis by propensity scoring to account for bias due to observed confounders. We think this study provides reliable data on the incidence of ARDS in patients with severe CAP, and that these data can be used for future studies in this important population. In addition, we assessed the association of ARDS with mortality in mechanically-ventilated patients to avoid potential bias due to worse outcomes associated with the need for ventilatory support.

Some limitations need to be addressed. First, the long period of recruitment (20 years) has undoubtedly been associated with major advances in patient care. Although we did incorporate advances in ventilatory management ${ }^{[10]}$ and other support measures ${ }^{[13]}$ over this time, our management protocol for CAP did not change substantially. We also allowed for this by including the period of admission when adjusting mortality outcomes. Second, this study was conducted at a single centre, which necessitates cautious extrapolation of the findings to other settings. Third, the Berlin definition requires the use of positive airway pressure, which is only applied to patients receiving ventilatory support. Fourth, the rate of respiratory viruses identified in our population may be underestimated since the diagnostic techniques employed were routinely implemented over the recruitment period.

In conclusion, ARDS complicating severe CAP occurs in $29 \%$ of ventilated patients, but is unrelated to either the aetiology or mortality. ARDS criteria should not be considered in the choice of the empiric antibiotic treatment in these patients. 


\section{Acknowledgments}

Dr Torres and Dr Ferrer are the guarantors of the entire manuscript, being responsible for all content, including the collected data and its analysis. We are indebted to the nursing staff and the attending physicians for their cooperation in this study. CC is in receipt of an ERS Short Term Fellowship and Postdoctoral Grant ("Strategic plan for research and innovation in health-PERIS 20162020 "). AC is receipt of an SEPAR-ALAT Fellowship.

Conflict of interest: The authors declare no conflict of interest. 


\section{REFERENCES}

[1] File TM, Jr., Marrie TJ. Burden of community-acquired pneumonia in North American adults. Postgrad Med 2010; 122: 130-141.

[2] Ewig S, Torres A. Community-acquired pneumonia as an emergency: time for an aggressive intervention to lower mortality. Eur Respir J 2011; 38: 253-60.

[3] Leoni D, Rello J. Severe community-acquired pneumonia: optimal management. Curr Opin Infect Dis 2017; 30: 240-247.

[4] Liapikou A, Ferrer M, Polverino E, Balasso V, Esperatti M, Piner R, Mensa J, Luque N, Ewig S, Menendez R, Niederman MS, Torres A. Severe Community-Acquired Pneumonia: Validation of the Infectious Diseases Society of America/American Thoracic Society Guidelines to Predict an Intensive Care Unit Admission. Clin Infect Dis 2009; 48: 377-85.

[5] Lenz H, Norby GO, Dahl V, Ranheim TE, Haagensen RE. Five-year mortality in patients treated for severe community-acquired pneumonia - a retrospective study. Acta Anaesthesiol Scand 2017; 61: 418-26.

[6] Woodhead M, Welch CA, Harrison DA, Bellingan G, Ayres JG. Community-acquired pneumonia on the intensive care unit: secondary analysis of 17,869 cases in the ICNARC Case Mix Programme Database. Crit Care 2006; 10 Suppl 2: S1.

[7] Cilloniz C, Ewig S, Polverino E, Marcos MA, Esquinas C, Gabarrus A, Mensa J, Torres A. Microbial aetiology of community-acquired pneumonia and its relation to severity. Thorax 2011; 66: 340-346.

[8] Cilloniz C, Ewig S, Polverino E, Munoz-Almagro C, Marco F, Gabarrus A, Menendez R, Mensa J, Torres A. Pulmonary complications of pneumococcal community-acquired pneumonia: incidence, predictors, and outcomes. Clin Microbiol Infect 2012; 18: 1132-42.

[9] Ceccato A, Torres A, Cilloniz C, Amaro R, Gabarrus A, Polverino E, Prina E, Garcia-Vidal C, Munoz-Conejero E, Mendez C, Cifuentes I, Puig de la Bella Casa, Menendez R, Niederman MS. Invasive Disease vs Urinary Antigen-Confirmed Pneumococcal Community-Acquired Pneumonia. Chest 2017; 151: 1311-19.

[10] Fan E, Del SL, Goligher EC, Hodgson CL, Munshi L, Walkey AJ, Adhikari NKJ, Amato MBP, Branson R, Brower RG, Ferguson ND, Gajic O, Gattinoni L, Hess D, Mancebo J, Meade MO, McAuley DF, Pesenti A, Ranieri VM, Rubenfeld GD, Rubin E, Seckel M, Slutsky AS, Talmor D, Thompson BT, Wunsch H, Uleryk E, Brozek J, Brochard LJ. An Official American Thoracic Society/European Society of Intensive Care Medicine/Society of Critical Care Medicine Clinical Practice Guideline: Mechanical Ventilation in Adult Patients with Acute Respiratory Distress Syndrome. Am J Respir Crit Care Med 2017; 195: 1253-63. 
[11] Thompson BT, Chambers RC, Liu KD. Acute Respiratory Distress Syndrome. N Engl J Med 2017; 377: 562-72.

[12] Ranieri VM, Rubenfeld GD, Thompson BT, Ferguson ND, Caldwell E, Fan E, Camporota L, Slutsky AS. Acute respiratory distress syndrome: the Berlin Definition. JAMA 2012; 307: 252633.

[13] Confalonieri M, Salton F, Fabiano F. Acute respiratory distress syndrome. Eur Respir Rev 2017; 26: pii: 160116.

[14] Bellani G, Laffey JG, Pham T, Fan E, Brochard L, Esteban A, Gattinoni L, van HF, Larsson A, McAuley DF, Ranieri M, Rubenfeld G, Thompson BT, Wrigge H, Slutsky AS, Pesenti A. Epidemiology, Patterns of Care, and Mortality for Patients With Acute Respiratory Distress Syndrome in Intensive Care Units in 50 Countries. JAMA 2016; 315: 788-800.

[15] Mandell LA, Wunderink RG, Anzueto A, Bartlett JG, Campbell GD, Dean NC, Dowell SF, File TM, Jr., Musher DM, Niederman MS, Torres A, Whitney CG. Infectious Diseases Society of America/American Thoracic Society consensus guidelines on the management of communityacquired pneumonia in adults. Clin Infect Dis 2007; 44 Suppl 2: S27-S72.

[16] Fine MJ, Auble TE, Yealy DM, Hanusa BH, Weissfeld LA, Singer DE, Coley CM, Marrie TJ, Kapoor WN. A prediction rule to identify low-risk patients with community-acquired pneumonia. $N$ Engl J Med 1997; 336: 243-50.

[17] Vincent JL, Moreno R, Takala J, Willatts S, De Mendonca A, Bruining H, Reinhart CK, Suter PM, Thijs LG. The SOFA (Sepsis-related Organ Failure Assessment) score to describe organ dysfunction/failure. On behalf of the Working Group on Sepsis-Related Problems of the European Society of Intensive Care Medicine. Intensive Care Med 1996; 22: 707-10.

[18] Cilloniz C, Polverino E, Ewig S, Aliberti S, Gabarrus A, Menendez R, Mensa J, Blasi F, Torres A. Impact of age and comorbidity on cause and outcome in community-acquired pneumonia. Chest 2013; 144: 999-1007.

[19] Ferguson ND, Fan E, Camporota L, Antonelli M, Anzueto A, Beale R, Brochard L, Brower R, Esteban A, Gattinoni L, Rhodes A, Slutsky AS, Vincent JL, Rubenfeld GD, Thompson BT, Ranieri VM. The Berlin definition of ARDS: an expanded rationale, justification, and supplementary material. Intensive Care Med 2012; 38: 1573-82.

[20] Restrepo MI, Mortensen EM, Rello J, Brody J, Anzueto A. Late admission to the ICU in patients with community-acquired pneumonia is associated with higher mortality. Chest 2010; 137 : 552-57.

[21] Vogelmeier CF, Criner GJ, Martinez FJ, Anzueto A, Barnes PJ, Bourbeau J, Celli BR, Chen R, Decramer M, Fabbri LM, Frith P, Halpin DM, Lopez Varela MV, Nishimura M, Roche N, Rodriguez-Roisin R, Sin DD, Singh D, Stockley R, Vestbo J, Wedzicha JA, Agusti A. Global Strategy for the Diagnosis, Management, and Prevention of Chronic Obstructive Lung Disease 2017 Report. GOLD Executive Summary. Am J Respir Crit Care Med 2017; 195: 557-82. 
[22] Cole TJ. Applied logistic regression. In: Hosmer DW, Lemeshow S, eds. New York: Wiley; 1989.

[23] Joffe MM, Rosenbaum PR. Invited commentary: propensity scores. Am J Epidemiol 1999; 150: 327-33.

[24] Healey JF. Statistics: a tool for social research. Belmont, CA: Wadsworth Publishing Company; 2011.

[25] Efron B and Tibshirani R. An introduction to the bootstrap (Monographs on statistics and applied probability. 1993. New York, Chapman and Hall.

Ref Type: Serial (Book,Monograph)

[26] Steyerberg E. Clinical Prediction Models. A Practical Approach to Development, Validation, and Updating. Springer; 2009.

[27] Fruchtman SM, Gombert ME, Lyons HA. Adult respiratory distress syndrome as a cause of death in pneumococcal pneumonia. Report of ten cases. Chest 1983; 83: 598-601.

[28] Torres A, Agusti A, Rodriguez-Roisin R, Martinez J, Agusti-Vidal A. ARDS and pneumococcal pneumonia. Chest 1984; 85: 584.

[29] Mannes GP, Boersma WG, Baur CH, Postmus PE. Adult respiratory distress syndrome (ARDS) due to bacteraemic pneumococcal pneumonia. Eur Respir J 1991; 4: 503-4.

[30] Mongardon N, Max A, Bougle A, Pene F, Lemiale V, Charpentier J, Cariou A, Chiche JD, Bedos JP, Mira JP. Epidemiology and outcome of severe pneumococcal pneumonia admitted to intensive care unit: a multicenter study. Crit Care 2012; 16: R155.

[31] Bernard GR, Artigas A, Brigham KL, Carlet J, Falke K, Hudson L, Lamy M, LeGall JR, Morris A, Spragg R. The American-European Consensus Conference on ARDS. Definitions, mechanisms, relevant outcomes, and clinical trial coordination. Am J Respir Crit Care Med 1994; 149: 81824.

[32] Ferrer M, Torres A, Martinez R, Ramirez P, Polverino E, Montull B, Sialer S, Niederman MS, Agusti A, Menendez R. Inhaled corticosteroids and systemic inflammatory response in community-acquired pneumonia: a prospective clinical study. Respirology 2014; 19: 929-35.

[33] Gutierrez P, Closa D, Piner R, Bulbena O, Menendez R, Torres A. Macrophage activation in exacerbated chronic obstructive pulmonary disease with and without community-acquired pneumonia. Eur Respir J 2010; 36: 285-91.

[34] Butt Y, Kurdowska A, Allen TC. Acute Lung Injury: A Clinical and Molecular Review. Arch Pathol Lab Med 2016; 140: 345-50.

[35] Torres A, Cilloniz C, Ferrer M, Gabarrus A, Polverino E, Villegas S, Marco F, Mensa J, Menendez $R$, Niederman $M$. Bacteraemia and antibiotic-resistant pathogens in community acquired pneumonia: risk and prognosis. Eur Respir J 2015; 45: 1353-63. 
[36] Ferrer M, Travierso C, Cilloniz C, Gabarrus A, Ranzani OT, Polverino E, Liapikou A, Blasi F, Torres A. Severe community-acquired pneumonia: Characteristics and prognostic factors in ventilated and non-ventilated patients. PLoS One 2018; 13: e0191721.

[37] Bos LD, Schouten LR, van Vught LA, Wiewel MA, Ong DSY, Cremer O, Artigas A, Martin-Loeches I, Hoogendijk AJ, Van Der PT, Horn J, Juffermans N, Calfee CS, Schultz MJ. Identification and validation of distinct biological phenotypes in patients with acute respiratory distress syndrome by cluster analysis. Thorax 2017; 72: 876-83.

[38] Famous KR, Delucchi K, Ware LB, Kangelaris KN, Liu KD, Thompson BT, Calfee CS. Acute Respiratory Distress Syndrome Subphenotypes Respond Differently to Randomized Fluid Management Strategy. Am J Respir Crit Care Med 2017; 195: 331-38.

[39] Di Pasquale M, Esperatti M, Crisafulli E, Ferrer M, Bassi GL, Rinaudo M, Escorsell A, Fernandez J, Mas A, Blasi F, Torres A. Impact of chronic liver disease in intensive care unit acquired pneumonia: a prospective study. Intensive Care Med 2013; 39: 1776-84.

[40] Ranzani OT, Ferrer M, Esperatti M, Giunta V, Bassi GL, Carvalho CR, Torres A. Association between systemic corticosteroids and outcomes of intensive care unit-acquired pneumonia. Crit Care Med 2012; 40: 2552-61.

[41] Martin-Loeches I, Torres A, Rinaudo M, Terraneo S, De RF, Ramirez P, Diaz E, Fernandez-Barat L, Li Bassi GL, Ferrer M. Resistance patterns and outcomes in intensive care unit (ICU)-acquired pneumonia. Validation of European Centre for Disease Prevention and Control (ECDC) and the Centers for Disease Control and Prevention (CDC) classification of multidrug resistant organisms. Journal of Infection 2015; 70: 213-22.

[42] Tejerina E, Frutos-Vivar F, Restrepo MI, Anzueto A, Palizas F, Gonzalez M, Apezteguia C, Abroug F, Matamis D, Bugedo G, Esteban A. Prognosis factors and outcome of communityacquired pneumonia needing mechanical ventilation. J Crit Care 2005; 20: 230-238.

[43] Pascual FE, Matthay MA, Bacchetti P, Wachter RM. Assessment of prognosis in patients with community-acquired pneumonia who require mechanical ventilation. Chest 2000; 117: 503-12.

[44] Lee JH, Ryu YJ, Chun EM, Chang JH. Outcomes and prognostic factors for severe communityacquired pneumonia that requires mechanical ventilation. Korean J Intern Med 2007; 22: 15763.

[45] Alvarez-Lerma F. Modification of empiric antibiotic treatment in patients with pneumonia acquired in the intensive care unit. ICU-acquired Pneumonia Study Group. Intensive Care Med 1996; 22: 387-94.

[46] Torres A, Sibila O, Ferrer M, Polverino E, Menendez R, Mensa J, Gabarrus A, Sellares J, Restrepo MI, Anzueto A, Niederman MS, Agusti C. Effect of corticosteroids on treatment failure among hospitalized patients with severe community-acquired pneumonia and high inflammatory response: a randomized clinical trial. JAMA 2015; 313: 677-86. 
[47] Wan YD, Sun TW, Liu ZQ, Zhang SG, Wang LX, Kan QC. Efficacy and Safety of Corticosteroids for Community-Acquired Pneumonia: A Systematic Review and Meta-Analysis. Chest 2016; 149: 209-19.

[48] Welte T, Dellinger RP, Ebelt H, Ferrer M, Opal SM, Schliephake DE, Wartenberg-Demand A, Werdan K, Loffler K, Torres A. Concept for a study design in patients with severe communityacquired pneumonia: $A$ randomised controlled trial with a novel IGM-enriched immunoglobulin preparation - The CIGMA study. Respir Med 2015; 109: 758-67. 


\section{FIGURE LEGEND}

Figure 1: Flow diagram of the study population.

Abbreviations: ARDS = acute respiratory distress syndrome; CAP = community-acquired pneumonia; $\mathrm{ICU}=$ intensive care unit; IMV = invasive mechanical ventilation; NIMV = non-invasive mechanical ventilation.

Figure 1

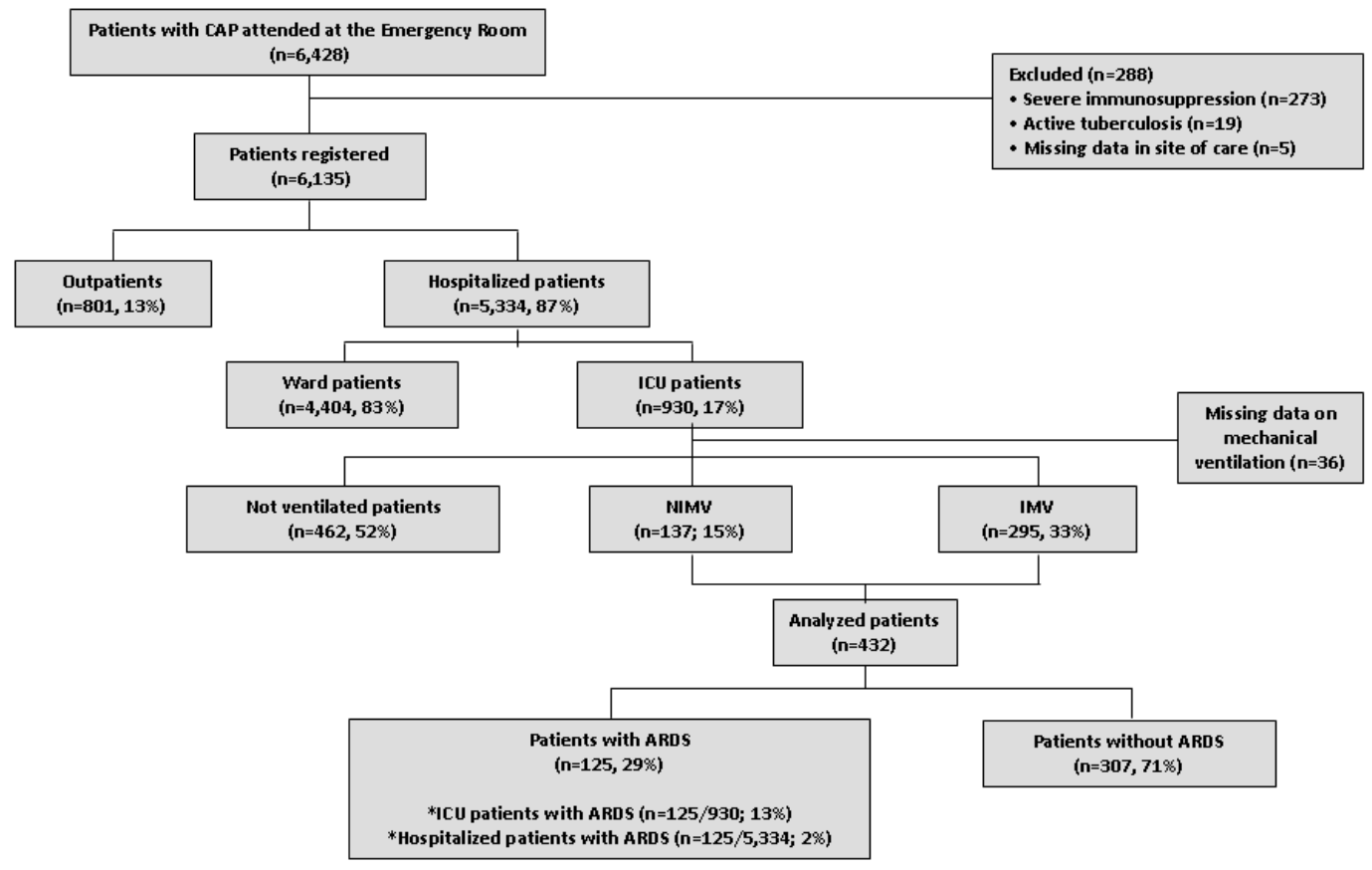


Table 1: Characteristics of patients at baseline

\begin{tabular}{|c|c|c|c|}
\hline Variables & $\begin{array}{c}\text { Non-ARDS patients } \\
\qquad n=307\end{array}$ & $\begin{array}{l}\text { ARDS patients } \\
\qquad n=125\end{array}$ & p-value \\
\hline Age, mean (SD), years & $65.8(14.4)$ & $63.1(17.3)$ & 0.26 \\
\hline Male sex, $\mathrm{n}(\%)$ & $212(69)$ & $75(60)$ & 0.071 \\
\hline Current smoker, $\mathrm{n}(\%)$ & $93(31)$ & $34 / 122(28)$ & 0.53 \\
\hline Current alcohol abuse, $n(\%)$ & $66(22)$ & $34(28)$ & 0.21 \\
\hline Previous antibiotic, $\mathrm{n}(\%)^{a}$ & $46(17)$ & $29(25)$ & 0.052 \\
\hline Influenza vaccine, $\mathrm{n}(\%)$ & $66(38)$ & $26(34)$ & 0.62 \\
\hline Pneumococcal vaccine, $\mathrm{n}(\%)$ & $33(18)$ & $7(9)$ & 0.054 \\
\hline Inhaled corticosteroids, n (\%) & $80(27)$ & $18(15)$ & 0.008 \\
\hline Systemic corticosteroids, n (\%) & $13(6)$ & $8(8)$ & 0.41 \\
\hline Previous episode of pneumonia, $n$ (\%) & $29(11)$ & $7(6)$ & 0.18 \\
\hline Nursing home resident, $\mathrm{n}(\%)$ & $16(5 \%)$ & $5(4 \%)$ & 0.62 \\
\hline Co-morbidity, $\mathrm{n}(\%)^{\mathrm{b}}$ & $244(81)$ & $83(66)$ & 0.002 \\
\hline Chronic respiratory disease & $152(51)$ & $45(37)$ & 0.009 \\
\hline COPD & $105(36)$ & $26(22)$ & 0.005 \\
\hline Asthma & $9(3)$ & $4(3)$ & 0.89 \\
\hline Bronchiectasis & $8(3)$ & $2(2)$ & 0.73 \\
\hline Other ${ }^{c}$ & $30(10)$ & $13(11)$ & 0.85 \\
\hline Chronic cardiovascular disease & $52(17)$ & $20(16)$ & 0.76 \\
\hline Diabetes mellitus & $75(25)$ & $26(21)$ & 0.38 \\
\hline Neurological disease & $46(16)$ & $20(17)$ & 0.84 \\
\hline Chronic renal disease & $27(9)$ & $8(6)$ & 0.37 \\
\hline Chronic liver disease & $26(9)$ & $12(10)$ & 0.74 \\
\hline
\end{tabular}

Abbreviations: ARDS = acute respiratory distress syndrome; COPD = chronic obstructive pulmonary disease. Percentages were calculated for non-missing data. ${ }^{a}$ Information on previous antibiotics was obtained in 67 (89\%) cases without any significant differences in the type of antibiotics each group had received: beta-lactams ( 38 cases), Fluoroquinolons ( 12 cases), Macrolides ( 9 cases), and other (8 cases). ${ }^{\mathrm{b}}$ Some patients may have more than 1 co-morbid condition. ${ }^{\mathrm{c}}$ Other respiratory diseases included the sequelae of pulmonary tuberculosis, pulmonary hypertension, and interstitial lung disease. 
Table 2: Characteristics of patients at admission

\begin{tabular}{|c|c|c|c|}
\hline Variables & $\begin{array}{l}\text { Non-ARDS patients } \\
\qquad n=307\end{array}$ & $\begin{array}{l}\text { ARDS patients } \\
\qquad n=125\end{array}$ & p-value \\
\hline Mechanical ventilation, $\mathrm{n}(\%)$ & & & 0.55 \\
\hline Non-invasive & $100(33)$ & $37(30)$ & \\
\hline Invasive & 207 (67) & $88(70)$ & \\
\hline \multicolumn{4}{|c|}{ Laboratory findings, median (IQR) } \\
\hline Creatinine, $\mathrm{mg} / \mathrm{dL}$ & $1.3(1 ; 1.8)$ & $1.3(0.9 ; 2)$ & 0.52 \\
\hline C-reactive protein, $\mathrm{mg} / \mathrm{dL}$ & $20.7(9.5 ; 30)$ & $22.3(14.8 ; 30.2)$ & 0.15 \\
\hline $\mathrm{PaO}_{2} / \mathrm{FiO}_{2}$ & $233(176 ; 296)$ & $195(151 ; 241)$ & $<0.001$ \\
\hline SOFA score, median (IQR) ${ }^{\mathrm{a}}$ & $4(3 ; 6)$ & $5(3 ; 6)$ & 0.026 \\
\hline PSI score, median (IQR) & $123(101 ; 143)$ & $116(81 ; 139)$ & 0.017 \\
\hline PSI risk class, $\mathrm{n}(\%)^{\mathrm{b}}$ & & & 0.020 \\
\hline $\mid-I I I$ & $42(19)$ & $29(31)$ & \\
\hline IV-V & $180(81)$ & $65(69)$ & \\
\hline Bacteremia, n (\%) & $46(19)$ & $20(19)$ & 0.98 \\
\hline Pleural effusion, $\mathrm{n}(\%)$ & $65(22)$ & $22(18)$ & 0.37 \\
\hline Multilobar, n (\%) & $97(32)$ & $125(100)$ & $<0.001$ \\
\hline Septic shock, n (\%) & $106(36)$ & $45(37)$ & 0.87 \\
\hline Acute renal failure, $\mathrm{n}(\%)$ & $140(47)$ & $61(50)$ & 0.63 \\
\hline
\end{tabular}

Abbreviations: $A R D S=$ acute respiratory distress syndrome; IQR = interquartile range; $\mathrm{PaO}_{2} / \mathrm{FiO}_{2}=$ arterial oxygen tension to inspired oxygen fraction ratio; $\mathrm{PSI}=$ pneumonia severity index; SOFA = sepsis-related organ failure assessment. Percentages were calculated on non-missing data. ${ }^{a}$ Higher SOFA in ARDS patients was due to a higher scoring in the respiratory component. ${ }^{b}$ Stratified according to 30-day risk mortality for community-acquired pneumonia: risk classes I-III ( $\leq 90$ points) have low predicted mortality (range, $0 \%-10 \%$ ), and risk classes IV-V (>90 points) have the highest predicted mortality (range, 10\%-35\%). 
Table 3: Microbial aetiology in the study population

\begin{tabular}{|c|c|c|c|}
\hline Pathogen & $\begin{array}{l}\text { Non-ARDS patients } \\
\qquad n=307\end{array}$ & $\begin{array}{l}\text { ARDS patients } \\
\qquad n=125\end{array}$ & p-value \\
\hline Patients with defined aetiology & $157(51)$ & $71(57)$ & 0.29 \\
\hline Streptococcus pneumoniae & $71(45)$ & $29(41)$ & 0.54 \\
\hline Respiratory viruses & $12(8)$ & $8(11)$ & 0.37 \\
\hline Atypical & $10(6)$ & $5(7)$ & $>0.99$ \\
\hline Mycoplasma pneumoniae & $5(3)$ & $4(6)$ & 0.47 \\
\hline Coxiella burnetii & $1(1)$ & $1(1)$ & 0.53 \\
\hline Chlamydophila pneumoniae & $4(3)$ & $0(0)$ & 0.31 \\
\hline Pseudomonas aeruginosa & $10(6)$ & $3(4)$ & 0.76 \\
\hline Staphylococcus aureus & $8(5)$ & $4(6)$ & $>0.99$ \\
\hline GNEB & $5(3)$ & $3(4)$ & 0.71 \\
\hline Escherichia coli & $3(2)$ & $3(4)$ & 0.38 \\
\hline Klebsiella pneumoniae & $2(1)$ & $0(0)$ & $>0.99$ \\
\hline Haemophilus influenzae & $5(3)$ & $2(3)$ & $>0.99$ \\
\hline Legionella pneumophila & $2(1)$ & $4(6)$ & 0.077 \\
\hline Streptococcus constellatus & $1(1)$ & $0(0)$ & $>0.99$ \\
\hline Moraxella catarrhalis & $1(1)$ & $0(0)$ & $>0.99$ \\
\hline Others & $2(1)$ & $0(0)$ & $>0.99$ \\
\hline Polymicrobial $^{\mathrm{a}}$ & $30(19)$ & $13(18)$ & 0.89 \\
\hline
\end{tabular}

Abbreviations: ARDS = acute respiratory distress syndrome; GNEB = Gram-negative enteric bacilli. Percentages calculated on non-missing data.

The percentages of pathogens are related to the number of patients with etiologic diagnosis in each group.

a Polymicrobial cases: S. pneumoniae + respiratory viruses; S. pneumoniae + H. influenzae; $S$. pneumoniae +atypical bacteria; S. pneumoniae + E. coli; S. pneumoniae + S. aureus, S. pneumoniae+ Acinetobacter spp.; S. pneumoniae +others, Respiratory viruses + H. influenzae; Respiratory viruses + $S$. aureus; Respiratory viruses $+P$. aeruginosa; Respiratory viruses + other; $P$. aeruginosa $+L$. pneumophila; $P$. aeruginosa $+K$. pneumoniae; $P$. aeruginosa + other; S. aureus+ M. Catarrhalis; $S$. aureus + atypical: $S$. aureus $+P$. aeruginosa . 
Table 4: Significant univariate and multivariate logistic regression analyses of ARDS predictors

\begin{tabular}{|c|c|c|c|c|c|c|}
\hline \multirow[t]{2}{*}{ Variable } & \multicolumn{3}{|c|}{ Univariate $^{a}$} & \multicolumn{3}{|c|}{ Multivariate $^{\mathrm{bc}}$} \\
\hline & OR & $95 \% \mathrm{Cl}$ & p-value & OR & $95 \% \mathrm{Cl}$ & $p$-value \\
\hline Year of occurrence of pneumonia $\geq 2007$ & 0.96 & 0.64 to 1.46 & 0.86 & 0.99 & 0.64 to 1.54 & 0.98 \\
\hline Age $(+1$ year $)$ & 0.99 & 0.98 to 1.00 & 0.12 & - & - & - \\
\hline Female sex & 1.49 & 0.97 to 2.29 & 0.071 & 1.52 & 0.97 to 2.39 & 0.067 \\
\hline Pneumococcal vaccination & 0.62 & 0.34 to 1.12 & 0.11 & - & - & - \\
\hline Inhaled corticosteroids & 0.45 & 0.26 to 0.77 & 0.004 & 0.48 & 0.27 to 0.85 & 0.012 \\
\hline Previous antibiotic & 1.60 & 0.99 to 2.61 & 0.057 & 1.80 & 1.08 to 2.98 & 0.024 \\
\hline Previous episode of pneumonia & 0.57 & 0.26 to 1.21 & 0.14 & - & - & - \\
\hline Chronic respiratory disease $^{d}$ & & & 0.076 & - & - & - \\
\hline Non-chronic respiratory disease & 1 & - & - & - & - & - \\
\hline COPD & 0.47 & 0.28 to 0.79 & 0.004 & - & - & - \\
\hline Asthma & 0.72 & 0.27 to 1.92 & 0.51 & - & - & - \\
\hline Bronchiectasis & 0.96 & 0.28 to 3.29 & 0.95 & - & - & - \\
\hline Other ${ }^{\mathrm{e}}$ & 0.81 & 0.40 to 1.63 & 0.55 & - & - & - \\
\hline SOFA score $(+1 \text { point })^{f}$ & 1.12 & 1.03 to 1.22 & 0.007 & 1.13 & 1.03 to 1.23 & 0.009 \\
\hline Microbial etiology & & & 0.36 & & & 0.37 \\
\hline Unknown & 1 & - & - & - & - & - \\
\hline Streptococcus pneumoniae & 1.10 & 0.67 to 1.82 & 0.70 & 1.17 & 0.69 to 1.97 & 0.56 \\
\hline Other & 1.45 & 0.87 to 2.41 & 0.15 & 1.46 & 0.86 to 2.47 & 0.16 \\
\hline
\end{tabular}


Abbreviations: $\mathrm{ARDS}=$ acute respiratory distress syndrome; $\mathrm{Cl}=$ confidence interval; $\mathrm{COPD}=$ chronic obstructive pulmonary disease; OR = odds ratio; SOFA = sepsis-related organ failure assessment. Data are shown as estimated ORs $(95 \% \mathrm{Cls})$ of the explanatory variables in the ARDS group. The OR is defined as the probability of having ARDS divided by the probability of not having ARDS. The $p$-value is based on the null hypothesis that all ORs relating to an explanatory variable equal unity (no effect).

a The variables analyzed in the univariate analyses were as follows: age, gender, influenza and pneumococcal vaccination, systemic and inhaled corticosteroids, prior antibiotic treatment, chronic pulmonary disease, chronic cardiovascular disease, chronic renal disease, chronic liver disease, diabetes mellitus, neurological disease, pneumonia in the past year, nursing home resident, C-reactive protein, and SOFA score.

${ }^{b}$ Adjusted for the propensity score, the year of occurrence of pneumonia, and the microbial etiology.

${ }^{c}$ Hosmer-Lemeshow goodness-of-fit test, $p=0.35$.

${ }^{d}$ The $p$-value corresponds to differences between the five groups (non-chronic respiratory disease, COPD/chronic bronchitis, asthma, bronchiectasis, or other chronic respiratory diseases).

${ }^{\mathrm{e}}$ Other chronic respiratory diseases include sequelae of pulmonary tuberculosis, pulmonary hypertension, and interstitial lung disease.

${ }^{f}$ The p-value corresponds to differences between the three groups (unknown etiology, Streptococcus pneumoniae, or other etiologies). 
Table 5: Clinical Outcomes

\begin{tabular}{lccc}
\hline Variables & $\begin{array}{c}\text { Non-ARDS patients } \\
\mathbf{n}=\mathbf{3 0 7}\end{array}$ & $\begin{array}{c}\text { ARDS patients } \\
\mathbf{n = 1 2 5}\end{array}$ & -value \\
\hline Length of hospital stay, median (IQR), days & $15(10 ; 27)$ & $16(9 ; 30)$ & 0.96 \\
ICU mortality, n (\%) & $70(23)$ & $37(30)$ & 0.14 \\
In-hospital mortality, n (\%) & $81(26)$ & $41(33)$ & 0.18 \\
30-day mortality, n (\%) & $90(30)$ & $44(35)$ & 0.25
\end{tabular}

Abbreviations: ARDS = acute respiratory distress syndrome; ICU = intensive care unit; IQR = interquartile range. Percentages were calculated for non-missing data. 
Table 6: Significant univariate and multivariate logistic regression analyses for predictors of 30-day mortality

\begin{tabular}{|c|c|c|c|c|c|c|}
\hline \multirow[t]{2}{*}{ Variable } & \multicolumn{4}{|c|}{ Univariate $^{a}$} & \multicolumn{2}{|c|}{ Multivariate $^{b c}$} \\
\hline & OR & $95 \% \mathrm{Cl}$ & p-value & OR & $95 \% \mathrm{Cl}$ & p-value \\
\hline Year of occurrence of pneumonia $\geq 2007$ & 0.56 & 0.37 to 0.84 & 0.005 & 0.69 & 0.42 to 1.14 & 0.15 \\
\hline Age (+1 year) & 1.02 & 1.01 to 1.04 & 0.002 & 1.03 & 1.01 to 1.05 & 0.002 \\
\hline Pneumococcal vaccination & 0.50 & 0.27 to 0.92 & 0.025 & 0.38 & 0.18 to 0.82 & 0.013 \\
\hline Previous antibiotic & 1.50 & 0.92 to 2.42 & 0.10 & 2.09 & 1.17 to 3.72 & 0.012 \\
\hline Previous episode of pneumonia & 0.43 & 0.20 to 0.96 & 0.039 & 0.33 & 0.14 to 0.81 & 0.016 \\
\hline Chronic respiratory disease $^{d}$ & & & 0.017 & & & 0.040 \\
\hline Non-chronic respiratory disease & 1 & - & - & - & - & - \\
\hline COPD & 0.94 & 0.58 to 1.50 & 0.78 & 0.85 & 0.46 to 1.59 & 0.62 \\
\hline Asthma & 0.37 & 0.11 to 1.28 & 0.12 & 0.28 & 0.06 to 1.26 & 0.096 \\
\hline Bronchiectasis & 0.77 & 0.20 to 2.92 & 0.70 & 0.77 & 0.17 to 3.46 & 0.74 \\
\hline Other ${ }^{\mathrm{e}}$ & 2.53 & 1.31 to 4.89 & 0.006 & 2.42 & 1.09 to 5.35 & 0.029 \\
\hline Chronic cardiovascular disease & 2.11 & 1.26 to 3.53 & 0.005 & 1.97 & 1.07 to 3.61 & 0.029 \\
\hline Chronic liver disease & 2.58 & 1.33 to 5.01 & 0.005 & 2.35 & 1.09 to 5.06 & 0.029 \\
\hline Diabetes mellitus & 1.42 & 0.89 to 2.26 & 0.14 & - & - & - \\
\hline SOFA score (+1 point) & 1.28 & 1.17 to 1.40 & $<0.001$ & 1.25 & 1.09 to 1.43 & 0.001 \\
\hline Inadequate antibiotic therapy & 2.72 & 1.59 to 4.65 & $<0.001$ & 2.55 & 1.30 to 4.99 & 0.006 \\
\hline Microbial aetiology ${ }^{f}$ & & & 0.15 & & & 0.30 \\
\hline Unknown & 1 & - & - & 1 & - & - \\
\hline
\end{tabular}




\begin{tabular}{|c|c|c|c|c|c|c|}
\hline \multirow[t]{2}{*}{ Variable } & \multicolumn{4}{|c|}{ Univariate $^{\mathrm{a}}$} & \multicolumn{2}{|c|}{ Multivariate $^{b c}$} \\
\hline & OR & $95 \% \mathrm{Cl}$ & p-value & OR & $95 \% \mathrm{Cl}$ & p-value \\
\hline Streptococcus pneumoniae & 1.44 & 0.89 to 2.34 & 0.14 & 1.57 & 0.78 to 3.16 & 0.20 \\
\hline Others & 1.58 & 0.95 to 2.61 & 0.078 & 1.60 & 0.78 to 3.28 & 0.20 \\
\hline ARDS & 1.31 & 0.84 to 2.04 & 0.23 & 1.06 & 0.49 to 2.32 & 0.88 \\
\hline Interaction microbial etiology $\times \mathrm{ARDS}^{\mathrm{g}}$ & & & 0.33 & & & 0.65 \\
\hline Streptococcus pneumoniae $\times$ ARDS & 1.62 & 0.56 to 4.69 & 0.38 & 1.64 & 0.48 to 5.53 & 0.43 \\
\hline Other $\times$ ARDS & 0.67 & 0.22 to 1.99 & 0.47 & 0.93 & 0.27 to 3.21 & 0.90 \\
\hline
\end{tabular}

Abbreviations: ARDS = acute respiratory distress syndrome; $\mathrm{Cl}=$ confidence interval; OR = odds ratio; $\mathrm{PSI}=$ pneumonia severity index; SOFA = sepsis-related organ failure assessment. Data are shown as estimated ORs (95\% Cls) of the explanatory variables in the 30-day mortality group. The OR is defined as the probability of 30-day mortality divided by the probability of no 30-day mortality. The p-value is based on the null hypothesis that all ORs relating to an explanatory variable equal unity (no effect).

${ }^{a}$ The variables analyzed in the univariate analyses were: age, gender, influenza and pneumococcal vaccination, systemic and inhaled corticosteroids, prior antibiotic treatment, chronic pulmonary disease, chronic cardiovascular disease, chronic renal disease, chronic liver disease, diabetes mellitus, neurological disease, pneumonia in the past year, nursing home resident, creatinine, C-reactive protein, SOFA score, and inadequate antibiotic therapy.

${ }^{b}$ Adjusted for the propensity score, the year of occurrence of pneumonia, the ARDS, the microbial etiology, and the interaction between ARDS and microbial etiology.

${ }^{c}$ Hosmer-Lemeshow goodness-of-fit test, $p=0.27$.

${ }^{d}$ The p-value corresponds to differences between the five groups (non-chronic respiratory disease, COPD/chronic bronchitis, asthma, bronchiectasis, or other chronic respiratory diseases).

${ }^{\text {e }}$ Other chronic respiratory diseases include sequelae of pulmonary tuberculosis, pulmonary hypertension, and interstitial lung disease.

${ }^{f}$ The p-value corresponds to differences between the three groups (unknown etiology, Streptococcus pneumoniae, or other etiologies).

${ }^{g}$ The $p$-value corresponds to the interaction between microbial etiology and ARDS. 


\section{Supplementary Material}

\section{Acute Respiratory Distress Syndrome in Hospitalized Patients with Community-Acquired}

\section{Pneumonia}

Catia Cilloniz ${ }^{1}$, Miquel Ferrer ${ }^{1}$, Adamantia Liapikou ${ }^{2}$, Carolina Garcia-Vidal ${ }^{4}$, Albert Gabarrus ${ }^{1}$, Adrian Ceccato $^{1}$, Jorge Puig de La Bella Casa ${ }^{3}$,Francesco Blasi ${ }^{4}$,Antoni Torres ${ }^{1}$ MD 


\section{Extended methods}

\section{Study design and patients}

We performed a prospective observational cohort study of consecutive adult patients with community-acquired pneumonia (CAP) who were transferred to our intensive care unit (ICU) within 24 hours of hospital admission. The study was conducted between November 1996 and December 2016 at the Hospital Clinic, Barcelona, which is a 700-bed tertiary care university hospital. The inclusion criteria were as follows: 1) patients meeting the Infectious Disease Society of America/American Thoracic Society (IDSA/ATS) criteria for severe CAP [1] who were admitted to the ICU, including associated intermediate care units; and 2) patients who received either invasive mechanical ventilation (IMV) or non-invasive mechanical ventilation (NIMV) during the first 24 hours of hospital admission. Patients were excluded if they had active tuberculosis or severe immunosuppression. The latter included the following: neutropenia after chemotherapy or hematopoietic transplantation; drug-induced immunosuppression because of solid-organ transplantation, long-term corticosteroid treatment ( $>10 \mathrm{mg} /$ day), or cytotoxic therapy; and all patients infected with HIV.

\section{Data collection and evaluation}

The following parameters were recorded at admission: age, sex, smoking, alcohol and drug consumption, co-morbidities, antibiotic treatment in the 30 days before hospital admission, treatment with oral and inhaled corticosteroids, clinical signs and symptoms, arterial blood gas measurements, chest radiograph findings. Co-morbidities included chronic respiratory disease (e.g., chronic obstructive pulmonary disease [COPD], asthma, and bronchiectasis), diabetes mellitus, and chronic cardiovascular, neurological, renal, or liver disease. Clinical symptoms of interest were fever, cough, pleuritic chest pain, dyspnea, mental confusion, and aspiration, while signs of interest were blood pressure, body temperature, respiratory rate, and heart rate.

All chest $x$-rays were reviewed by at least two co-authors, either as part of the medical team of the ICU (MF, GLB, AT) or as attending physicians (AC, OR, CGV). For chest $x$-rays, we recorded the number of lobes affected, and the presence or absence of pleural effusion and atelectasis. Agreement by at least two co-authors was required to define a case as acute respiratory distress syndrome (ARDS) or non-ARDS.

We also assessed laboratory parameters (e.g., hemoglobin level, white blood cell count, platelet count, serum creatinine, and C-reactive protein), diagnostic procedures, empiric antibiotic therapy, ventilatory support (IMV and NIMV), pulmonary complications (e.g., empyema, pleural effusion, and surgical pleural draining), other clinical events (e.g., cardiac arrhythmias, septic shock, and acute renal failure). The duration of treatment, length of hospitalization, and mortality were also noted. Finally, we calculated the Pneumonia Severity Index (PSI) [2] and the Sepsis-related Organ Failure Assessment (SOFA) [3] scores at hospital and ICU admissions.

\section{Microbiological evaluation and diagnostic criteria}

Microbiological examination was performed in sputum, urine, nasopharyngeal swabs and two blood samples. Pleural puncture, tracheobronchial aspirates and bronchoalveolar lavage fluid, when available, were collected for Gram and Ziehl-Neelsen stains, and for bacterial, fungal, and mycobacterial cultures.

Lower respiratory tract samples and blood samples were obtained in the emergency department for bacterial culture before the start of antibiotic therapy. Nasopharyngeal swabs for respiratory virus 
detection and urine samples for S. pneumoniae and Legionella pneumophila antigen detection were obtained within 24 hours of hospital admission. Blood samples for atypical pathogen and respiratory virus serology were taken at admission and in the third and sixth weeks thereafter. The criteria used for etiological diagnosis have been reported previously [4].

\section{Definitions}

Pneumonia was defined as a new pulmonary infiltrate on chest $\mathrm{x}$-ray at hospital admission, with symptoms and signs compatible with a lower respiratory tract infection. A prior episode of pneumonia was defined as a case of pneumonia within the past 12 months. Severe CAP was defined according to when at least one major or three minor criteria of the IDSA/ATS guidelines were present [1] or if the patient was admitted to the ICU.

ARDS was identified by applying the Berlin definition in the first 24 hours after hospital admission [5]: new or worsening respiratory symptoms, bilateral pulmonary radiologic opacities not fully explained by effusions, lobar/lung collapse or nodules and not fully explained by cardiac failure or fluid overload, and a $\mathrm{PaO}_{2} / \mathrm{FiO}_{2}$ (i.e., partial pressure of oxygen in arterial blood/fraction of inspired oxygen) $\leq 300 \mathrm{mmHg}$ with a positive end-expiratory pressure or continuous positive airway pressure $>5 \mathrm{cmH}_{2} \mathrm{O}[5,6]$. The severity of ARDS was divided into three categories: mild $\left(200<\mathrm{PaO}_{2} / \mathrm{FiO}_{2} \leq 300\right.$ $\mathrm{mmHg})$, moderate $\left(100<\mathrm{PaO}_{2} / \mathrm{FiO}_{2} \leq 200 \mathrm{mmHg}\right)$ and severe $\left(\mathrm{PaO}_{2} / \mathrm{FiO}_{2}<100 \mathrm{mmHg}\right)[5]$. We chose the initial 24 hours to differentiate as ARDS and non-ARDS patients because this period of time is considered the limit to differentiate between clinical features at admission and worsening evolution in the hospital [7]. COPD was defined according to the criteria of the 2017 GOLD strategy [8].

\section{Clinical outcomes}

The primary outcome was 30-day mortality. Other outcomes were the hospitalization length, and the ICU and in-hospital mortality rates. Patients were followed for 30 days or until hospital discharge, whichever was the longest period.

\section{Ethics statement}

The study was approved by the ethics committee of our institution (no. 2009/5451). The need for written informed consent was waived due to the non-interventional design.

\section{Statistical analysis}

All analyses were performed using IBM SPSS Statistics version 23.0 (IBM Corp., Armonk, NY, USA). The level of significance was set at 0.05 (2-tailed), unless otherwise specified. We used a logistic regression model to identify factors associated with ARDS (1). Factors were included in the multivariate model when univariate comparisons yielded a level of significance of $p<0.15$. We tested the following variables: age (years), gender (male vs female), influenza and pneumococcal vaccination status (no vs yes), systemic and inhaled corticosteroid use (no vs yes), prior antibiotic treatment (no vs yes), chronic pulmonary disease (no disease vs. COPD vs chronic bronchitis vs asthma vs bronchiectasis vs other), chronic cardiovascular disease (no vs yes), chronic renal disease (no vs yes), chronic liver disease (no vs yes), diabetes mellitus (no vs yes), neurological disease (no vs yes), pneumonia in the past year (no vs yes), nursing home resident (no vs yes), C-reactive protein $(\mathrm{mg} / \mathrm{dL})$, and SOFA score (points). A backward stepwise selection $\left(\mathrm{p}_{\text {in }}<0.05, \mathrm{p}_{\text {out }}<0.10\right)$ was used to identify factors predictive of ARDS.

The factors associated with the 30-day mortality were also assessed by univariate and multivariate analyses (using the same inclusion criterion, $p<0.15$ ). Inadequate antibiotic therapy (no vs yes) was also tested for 30-day mortality. A propensity score for patients with ARDS was developed (2), 
irrespective of the outcome, through a multivariate logistic regression to predict the influence of the 14 predetermined variables on the presence of ARDS. We included variables in the propensity score calculation based on the methods of Brookhart et al. (3), plus any variables associated with ARDS and clinical outcomes. Finally, we performed a logistic regression analysis to predict 30-day mortality by incorporating the propensity score, the year of occurrence of pneumonia, the presence of ARDS, the microbial etiology, and the interaction between ARDS and microbial etiology. This included all risk factors with an association in the univariate analyses $(p<0.15)$, calculated in a stepwise backward elimination procedure $\left(p_{\text {in }}<0.05, p_{\text {out }}<0.10\right)$. To identify collinearity, we calculated the $r$ coefficient between two independent variables, and if they were highly correlated $(r>| \pm 0.30|)$, the variable with the largest variance was excluded from multivariate analysis (4) The analyses were repeated for the subset of patients with pneumococcal CAP.

We investigated the missing data patterns for covariates and assumed missing at random condition for covariates (5). We then used multiple imputation (6) to generate five datasets to evaluate the prediction performance for ARDS and 30-day mortality. The model for multiple imputation included all covariates of the risk models, plus ARDS and 30-day mortality. To simplify the performance evaluation, we filled in missing values with the first set of imputed values from the multiple imputation. 
Online Table 1: Empiric antibiotic treatment in the study population

\begin{tabular}{|c|c|c|c|}
\hline Therapy & $\begin{array}{l}\text { Non-ARDS patients } \\
\qquad n=307\end{array}$ & $\begin{array}{l}\text { ARDS patients } \\
\qquad n=125\end{array}$ & p-value \\
\hline Fluoroquinolones monotherapy & $16(5)$ & $3(2)$ & 0.18 \\
\hline$\beta$-lactam monotherapy & $15(5)$ & $3(2)$ & 0.22 \\
\hline Macrolide monotherapy & $2(1)$ & $0(0)$ & $>0.99$ \\
\hline Glycopeptide monotherapy & $0(0)$ & $1(1)$ & 0.30 \\
\hline$\beta$-lactam plus fluoroquinolone & $110(38)$ & $65(53)$ & 0.003 \\
\hline$\beta$-lactam plus macrolide & $95(33)$ & $35(29)$ & 0.44 \\
\hline$\beta$-lactam plus aminoglycoside & $17(6)$ & $3(3)$ & 0.15 \\
\hline Other combinations & $37(13)$ & $12(10)$ & 0.42 \\
\hline Inappropriate empiric treatment ${ }^{a}$ & $21(17)$ & $4(7)$ & 0.070 \\
\hline
\end{tabular}

Abbreviations: ARDS = acute respiratory distress syndrome. Percentages were calculated for nonmissing data.

${ }^{a}$ Calculated among patients with defined aetiology only.

The percentages of therapies are related to the numbers of patients receiving empiric antibiotic treatment in each group (292 patients in the non-ARDS group and 122 patients in the ARDS group). 
Online Table 2: Internal validation of the prediction model for ARDS, using the nonparametric bootstrap technique

\begin{tabular}{lcccc}
\hline Variable & Original & Bias & SE & $95 \%$ BCa Cl \\
\hline Year of occurrence of pneumonia $\geq 2007$ & -0.007 & 0.004 & 0.238 & -0.457 to 0.482 \\
Male sex & 0.421 & 0.008 & 0.241 & -0.050 to 0.924 \\
Inhaled corticosteroids & -0.726 & -0.037 & 0.307 & -1.356 to -0.236 \\
Previous antibiotic & 0.585 & 0.010 & 0.280 & 0.040 to 1.168 \\
SOFA score & 0.118 & 0.001 & 0.047 & 0.027 to 0.214 \\
Microbial aetiology & & & & \\
Streptococcus pneumoniae & 0.156 & -0.012 & 0.280 & -0.395 to 0.687 \\
Other & 0.377 & 0.001 & 0.271 & -0.137 to 0.877 \\
\hline
\end{tabular}

Abbreviations: $A R D S=$ acute respiratory distress syndrome; $\mathrm{BCa}=$ adjusted bootstrap; $\mathrm{Cl}=$ confidence interval; SE = standard error; SOFA, sepsis-related organ failure assessment. 
Online Table 3. Clinical outcomes of pneumococcal CAP

\begin{tabular}{lccc}
\hline Variables & $\begin{array}{c}\text { Patients with } \\
\text { non-ARDS } \\
\mathbf{n}=\mathbf{8 8}\end{array}$ & $\begin{array}{c}\text { Patients with } \\
\text { ARDS }\end{array}$ & p-value \\
& $\mathbf{n}=\mathbf{3 5}$ & \\
\hline Length of hospital stay, median (IQR), days & $15.5(11 ; 31.5)$ & $15(9 ; 31)$ & 0.46 \\
ICU mortality, n (\%) & $18(20)$ & $14(40)$ & 0.026 \\
In-hospital mortality, n (\%) & $23(26)$ & $15(43)$ & 0.070 \\
30-day mortality, n (\%) & $26(30)$ & $16(46)$ & 0.088 \\
\hline
\end{tabular}

Abbreviations: $A R D S=$ acute respiratory distress syndrome; $C A P=$ community-acquired pneumonia; ICU = intensive care unit; IQR = interquartile range.

Percentages calculated on non-missing data. 
Online Figure 1: ROC curve analysis of significant variables derived from the logistic regression model to predict ARDS

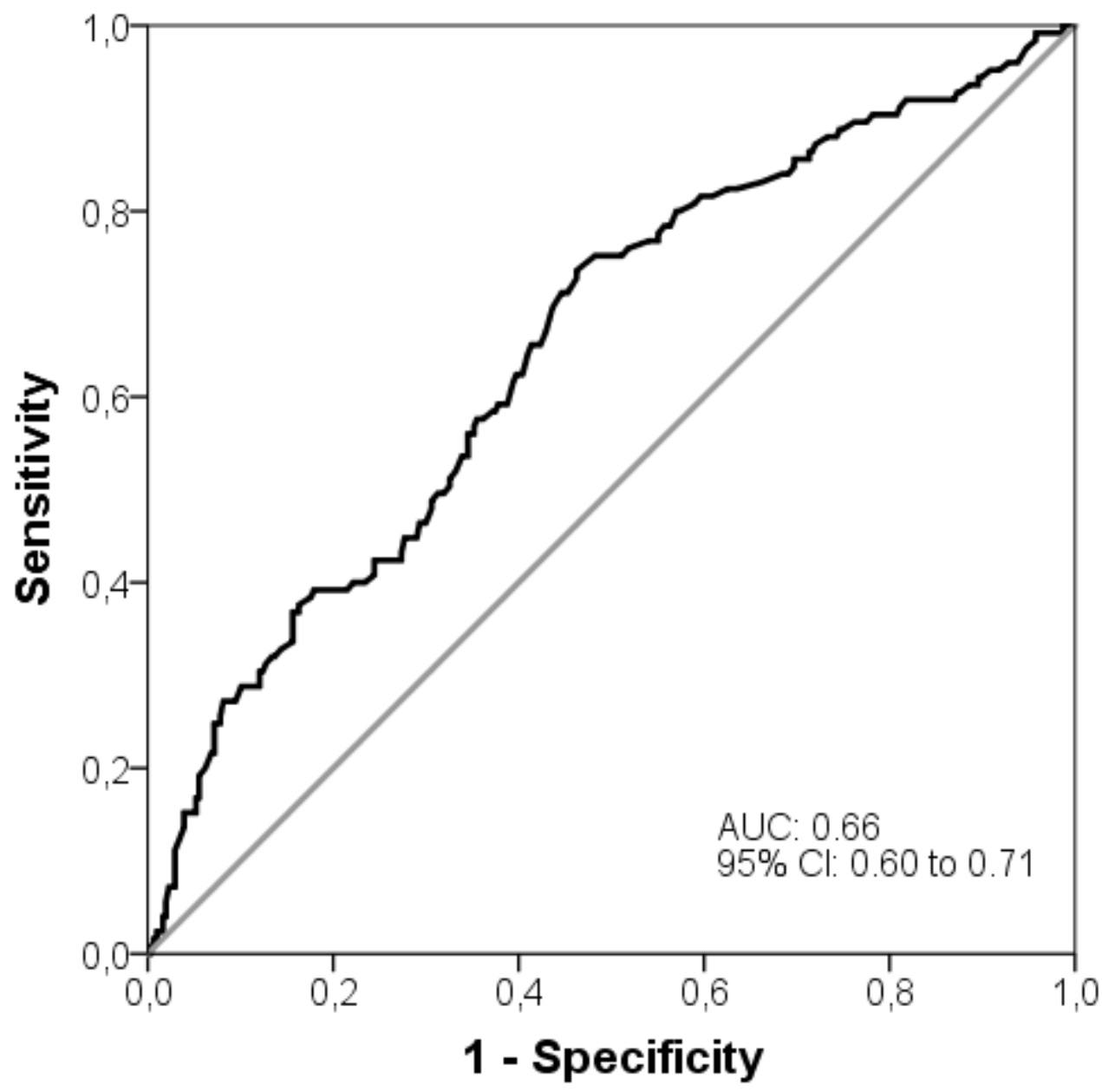

Abbreviations: AUC indicates area under the curve; ARDS = acute respiratory distress syndrome; $\mathrm{Cl}$, confidence interval; $\mathrm{ROC}$, receiver operating characteristic. 
Online Figure 2. ROC curve analysis of significant variables derived from the logistic regression model to predict 30-day mortality

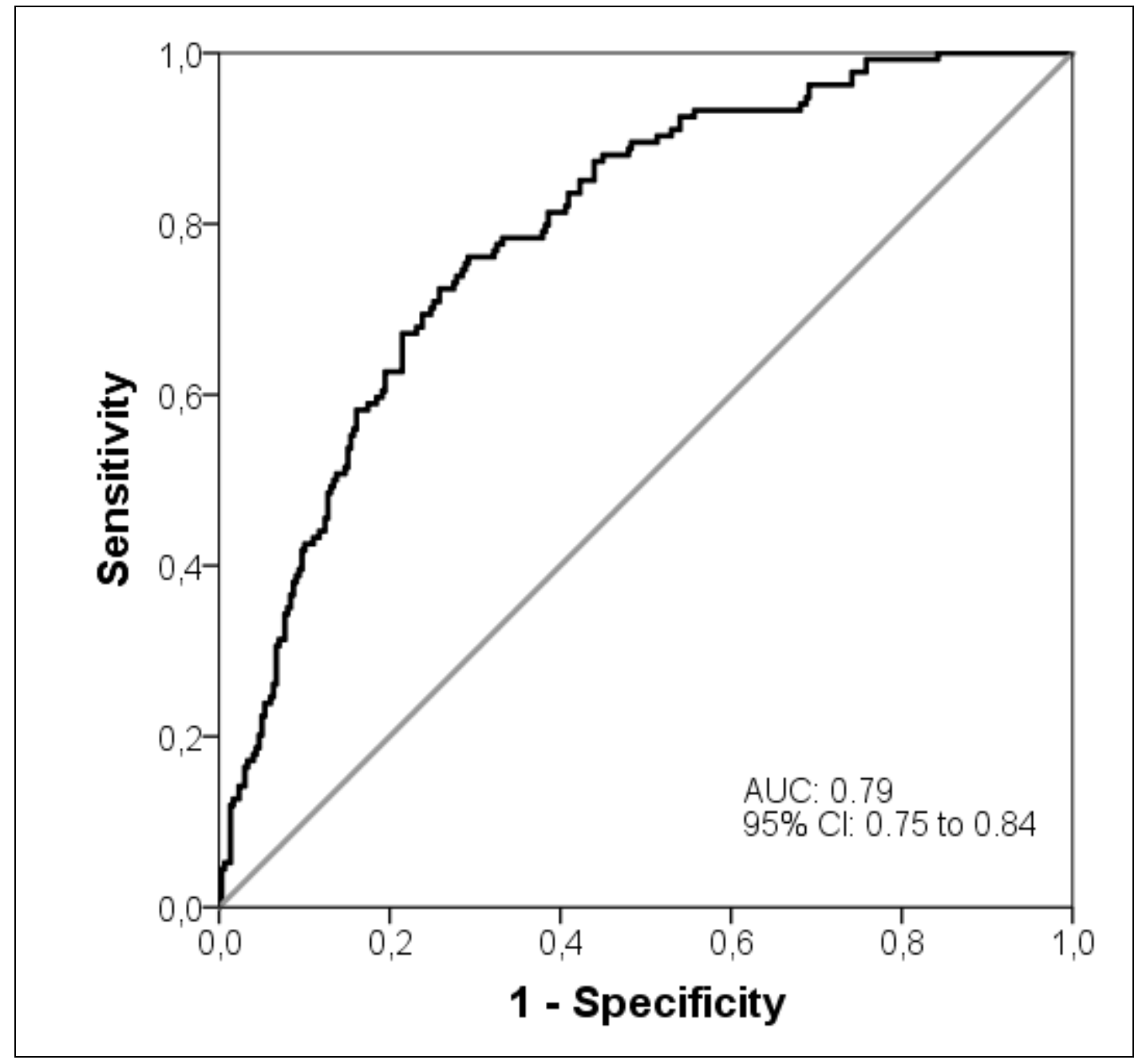

Abbreviations: AUC indicates area under the curve; $\mathrm{Cl}$, confidence interval; ROC, receiver operating characteristic. 


\section{REFERENCES}

[1] Mandell LA, Wunderink RG, Anzueto A, Bartlett JG, Campbell GD, Dean NC, Dowell SF, File TM, Jr., Musher DM, Niederman MS, Torres A, Whitney CG. Infectious Diseases Society of America/American Thoracic Society consensus guidelines on the management of community-acquired pneumonia in adults. Clin Infect Dis 2007; 44 Suppl 2: S27-S72.

[2] Fine MJ, Auble TE, Yealy DM, Hanusa BH, Weissfeld LA, Singer DE, Coley CM, Marrie TJ, Kapoor WN. A prediction rule to identify low-risk patients with community-acquired pneumonia. N Engl J Med 1997; 336: 243-50.

[3] Vincent JL, Moreno R, Takala J, Willatts S, De Mendonca A, Bruining H, Reinhart CK, Suter PM, Thijs LG. The SOFA (Sepsis-related Organ Failure Assessment) score to describe organ dysfunction/failure. On behalf of the Working Group on SepsisRelated Problems of the European Society of Intensive Care Medicine. Intensive Care Med 1996; 22: 707-10.

[4] Cilloniz C, Polverino E, Ewig S, Aliberti S, Gabarrus A, Menendez R, Mensa J, Blasi $F$, Torres A. Impact of age and comorbidity on cause and outcome in communityacquired pneumonia. Chest 2013; 144: 999-1007.

[5] Ranieri VM, Rubenfeld GD, Thompson BT, Ferguson ND, Caldwell E, Fan E, Camporota L, Slutsky AS. Acute respiratory distress syndrome: the Berlin Definition. JAMA 2012; 307: 2526-33.

[6] Ferguson ND, Fan E, Camporota L, Antonelli M, Anzueto A, Beale R, Brochard L, Brower R, Esteban A, Gattinoni L, Rhodes A, Slutsky AS, Vincent JL, Rubenfeld GD, Thompson BT, Ranieri VM. The Berlin definition of ARDS: an expanded rationale, justification, and supplementary material. Intensive Care Med 2012; 38: 1573-82.

[7] Restrepo MI, Mortensen EM, Rello J, Brody J, Anzueto A. Late admission to the ICU in patients with community-acquired pneumonia is associated with higher mortality. Chest 2010; 137: 552-57.

[8] Vogelmeier CF, Criner GJ, Martinez FJ, Anzueto A, Barnes PJ, Bourbeau J, Celli BR, Chen R, Decramer M, Fabbri LM, Frith P, Halpin DM, Lopez Varela MV, Nishimura $M$, Roche N, Rodriguez-Roisin R, Sin DD, Singh D, Stockley R, Vestbo J, Wedzicha JA, Agusti A. Global Strategy for the Diagnosis, Management, and Prevention of Chronic Obstructive Lung Disease 2017 Report. GOLD Executive Summary. Am J Respir Crit Care Med 2017; 195: 557-82. 